\title{
Advances in early biomarkers of diabetic nephropathy
}

\author{
JiN ZHANG ${ }^{1}$, JiANHUA LIU ${ }^{2}$, XIAOSONG QIN ${ }^{3 *}$ \\ ${ }^{1}$ Masters Student, Department of Laboratory Medicine, Shengjing Hospital of China Medical University, Shenyang, Liaoning, China \\ ${ }^{2} \mathrm{MD}$, PhD. Associate Professor of Laboratory Medicine, Department of Laboratory Medicine, Shengjing Hospital of China Medical University, Shenyang, Liaoning, China \\ ${ }^{3} \mathrm{MD}$. PhD. Professor of Laboratory Medicine, Department of Laboratory Medicine, Shengiing Hospital of China Medical University, Shenyang, Liaoning, China
}

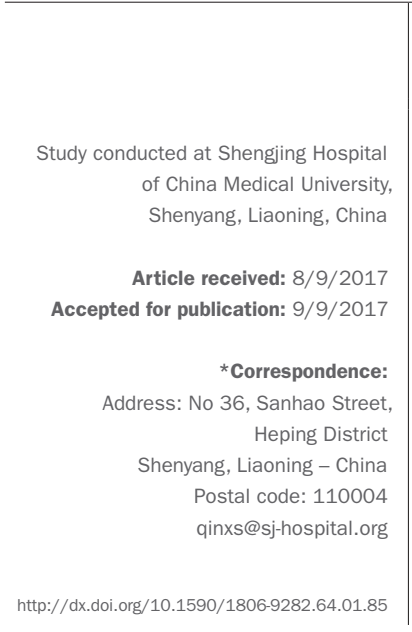

\section{SUMMARY}

Diabetic nephropathy is the main cause of chronic kidney disease, and represents the most common and serious complication of diabetes. The exact pathogenesis is complex and not elucidated. Several factors and mechanisms contribute to the development and outcome of diabetic nephropathy. An early diagnosis and intervention may slow down disease progression. A variety of biological markers associated with diabetic nephropathy were found in recent years, which was important for predicting the occurrence and development of the disease. Therefore, this article provides an overview of early biomarkers that are associated with diabetic nephropathy.

Keywords: Diabetes Mellitus. Diabetic Nephropathies. Biomarkers.

\section{INTRODUCTION}

Diabetes mellitus $(\mathrm{DM})$ is an endocrine and metabolic disease that has serious impact on human health. The morbidity and mortality of DM have risen continually at an alarming rate in recent years, and the population with diabetes mellitus is predicted to be about 439 million worldwide by $2030 .{ }^{1}$ The complications of DM include diabetic retinopathy, diabetic cardiovascular diseases and diabetic nephropathy (DN), which is the most common and serious complication of DM. DN has become the leading cause of chronic kidney failure, starting with normoalbuminuria, microalbuminuria, macroalbuminuria and ultimately leading to end stage renal disease (ESRD). ${ }^{2}$ For a long time, proteinuria has been considered the gold standard for evaluation and monitoring of renal function. However, renal function declines in about onethird of the patients before the occurrence of proteinuria, ${ }^{3}$ which makes it inadequate to detect proteinuria alone to monitor the incidence and progression of DN. Therefore, we need to look for laboratory biomarkers that are earlier than microalbuminuria or those appearing at the same time. This review focuses on the early biomarkers associated with the pathogenesis and pathology of DN and changes in renal function.

\section{BIOMARKERS ASSOCIATED WITH DN PATHOGENESIS}

A large number of prospective studies confirm that hyperglycemia is the most important risk factor for DN. ${ }^{4,5} \mathrm{Hy}$ - perglycemia promotes mitochondrial electron transport chain to generate excessive reactive oxygen species (ROS) through formation of the advanced glycation end products (AGEs) and activation of the polyol pathway, hexosamine pathway, protein kinase $\mathrm{C}(\mathrm{PKC})$ and angiotensin II. Then, the ROS initiate or enhance the oxidative stress and eventually cause the inflammatory response and formation of fibrosis. ${ }^{6,7}$ In addition, lipid metabolism abnormality, reninangiotensin-aldosterone system (RAAS) activation, systemic and glomerular hypertension, insulin signaling impairment, increased growth factors and pro-inflammatory cytokines, and intracellular signaling pathway activation also play a role in the occurrence and progression of $\mathrm{DN}$. 6.8

\section{Biomarkers of oxidative stress}

The occurrence and progression of DN is closely related with oxidative stress. Excessive ROS, which are induced by hyperglycemia, are involved in oxidative stress causing direct oxidation and damage of deoxyribonucleic acid (DNA), proteins and lipids. ${ }^{8,9}$

\section{Biomarkers of DNA injury}

8-hydroxy-2'-deoxyguanine (8-OHdG) is a sensitive biomarker of DNA damage to assess oxidative stress in the human body. In 1994, Ha et al. ${ }^{10}$ found that the 8-OHdG levels were significantly higher in cortex and nipples of diabetic mice induced by streptozotocin than in control mice, and they decreased after insulin treatment, which 
suggested that DN might be associated with oxidative stress and the formation of 8-OHdG. The following study by Hinokio et al. ${ }^{11}$ showed that urinary 8 -OHdG excretion in patients suffering from type 2 diabetes mellitus complicated by nephropathy was higher than in patients without complications or in healthy control subjects. Moreover, there was a correlation between urinary 8-OHdG level and glycosylated hemoglobin $\left(\mathrm{HbA}_{1 \mathrm{c}}\right)$. In this report, 8-OHdG was speculated to be a useful biomarker associated with complications secondary to DM. Zhao et al. ${ }^{12}$ measured the serum concentration of 8-OHdG using enzyme-linked immunosorbent assay (ELISA) and drew a similar conclusion. However, Serdar et al. demonstrated that there was no difference in urinary 8-OHdG levels between the groups with and without diabetic nephropathy on liquid chromatography-mass spectrometry, suggesting that 8-OHdG in urine was not a sensitive biomarker regarding albumin to creatinine ratio (UACR) for distinguishing DN patients from DM patients. ${ }^{13}$ Different biological fluids and methods might contribute to the lack of consistency in these studies, so that the predictive value of 8-OHdG in the early stages of DN needs further research to be determined.

\section{Biomarkers of protein and lipid injury}

Biomarkers associated with protein injury comprise pentosidine, 2,4-dinitrophenylhydrazine (DNPH) and advanced oxidation protein product (AOPP). F2-isoprostaglandin and 4-hydroxy-nonenal (HNE) are related to lipid injury. Calabrese et al. found that both urinary and serum levels of pentosidine, DNPH, F2-isoprostaglandin and HNE of DN patients were higher than those of control subjects. ${ }^{14}$ Tabak et al. showed that the level of AOPP in type 2 diabetes mellitus patients with complications such as DN and diabetic retinopathy was significantly higher than in patients without complications. ${ }^{15}$ These two studies have confirmed that oxidative stress damage is involved in the development of diabetic nephropathy.

\section{Biomarkers of glutathione antioxidant system and lipid peroxidation}

A growing number of studies reported that DM and its complications were closely related to oxidative stress, so we supposed that the biomarkers related to antioxidant defense system and lipid peroxidation (LPO) induced by free radicals may be potential biomarkers of kidney damage in diabetic patients. ${ }^{8}$ Glutathione s-transferase (GST), a kind of enzyme involved in cell detoxification, promotes inactivation and excretion of toxins by combining toxic drophobic compounds with glutathione. ${ }^{8}$
Experimental data from a study by Jiang et al. showed that the expression level of GST in diabetic rats induced by streptozotocin was remarkably higher than in control rats, suggesting that hyperglycemia may be the major cause for elevated GST. Eight weeks after treatment with resveratrol, the GST expression decreased and several indicators suggesting the occurrence of DN such as urinary protein excretion, creatinine, cellular apoptosis and renal hypertrophy were all improved, leading researchers to suppose that resveratrol likely played a role in renoprotection by lowering the expression level of GST. ${ }^{16}$ In agreement with GST, animal experiments on LPO have yielded the same results. ${ }^{17,18}$ In addition, genetic investigation also found that knockout of GST coding genes can lead to decreased GST levels and increased malondialdehyde (MDA) levels, an important biomarker of LPO, demonstrating that GST has an effect against oxidative stress. ${ }^{19}$

Human research was consistent with the experimental studies above. Compared with healthy subjects, increased activity of GST and increased level of MDA were found in type 2 diabetes mellitus patients. These results suggested that oxidative stress was involved in the occurrence of DM and GST was likely to play an important role in antioxidation..$^{20,21}$ In the study about GST and DN, Noce et al. reported that GST activity in type 2 diabetes mellitus patients with and without nephropathy were both significantly higher than that of control subjects, appearing to be closely related with the stages of DN and indicating that GST was likely to be a potential biomarker in early stage $\mathrm{DN} .^{22}$

\section{Biomarkers of inflammation}

Inflammatory response could be activated by biochemical, metabolic or hemodynamic disorders when a large number of white blood cells gather in the kidney. Then, proinflammatory cytokines and a variety of chemokines secreted by leukocytes may guide the latter into the kidney directly. Thus, a new cycle of inflammatory response is induced. The inflammatory cytokines and chemokines involved were hypothesized as potential biomarkers of DN. Liu et al. detected urinary levels of 27 kinds of inflammation-related factors of type 2 diabetes mellitus patients by multiplex- 27 bead immunoassay. They found that the levels of proinflammatory cytokines such as interleukin-8 (IL-8), tumor necrosis factor (TNF- $\alpha$ ) and chemokines such as monocyte chemoattractant protein-1 (MCP-1), interferon-inducible protein-10 (IP-10) in patients with microalbuminuria were all significantly higher than those of patients with normoalbuminuria and 
the control subjects. Besides, the levels of MCP-1 and IP-10 were positively correlated with proteinuria and $\mathrm{HbA}_{1 c}$, while negatively correlated with the estimated glomerular filtration rate (eGFR). ${ }^{23}$ These outcomes suggest that urinary inflammation-related factors may contribute to the diagnosis in early stages of DN.

In addition, some studies have shown that serum interleukin-18 (IL-18) level was elevated in DN patients and associated with $\mathrm{HbA}_{1 \mathrm{c}}$ or UACR, thus being speculated as a potential biomarker of diabetic nephropathy. ${ }^{24}$ On the other hand, the value of interleukin-6 (IL-6) in early diagnosis of diabetic nephropathy remains to be further confirmed. A number of studies have found that serum IL-6 levels of patients with normoalbuminuria or microalbuminuria were higher than those of control subjects and showed a positive correlation with UACR. ${ }^{25-28}$ However, some other studies have found that serum IL-6 level was elevated in patients with macroalbuminuria alone, and its early diagnosis value was not as good as that of urinary albumin excretion..$^{24,29}$

Some studies demonstrated that an increase in both urinary and serum levels of TNF- $\alpha$ in patients with nephropathy secondary to DM was found compared to those with normoalbuminuria and control subjects. Besides, levels of TNF- $\alpha$ in urine and serum were both significantly associated with urinary albumin excretion. These results revealed that TNF- $\alpha$ might be an early biomarker of kidney damage in diabetic patients. ${ }^{30,31}$ Soluble CD40 ligand $(\mathrm{sCD} 40 \mathrm{~L})$ is a transmembrane protein of the tumor necrosis factor superfamily and regulates inflammatory response by binding with CD40. A study by El-Asrar et al. ${ }^{32}$ showed that serum sCD40L level in type 1 diabetes mellitus patients with microangiopathy such as diabetic nephropathy, retinopathy or neuropathy was significantly higher than that of patients without complications and healthy control subjects, and diabetic patients without any of these complications presented higher sCD40L concentration as compared to healthy subjects. The researchers also found that serum SCD40L was significantly associated with the severity of kidney damage and the level of glycemic control. ${ }^{33}$

In addition to the biomarkers cited above, glycosyl hydrolase family of 18 members, including chitotriosidase (CHIT1) and cartilage glycoprotein 40 (YKL-40), commonly activated by macrophages cells and neutrophils, were also involved in the inflammatory response. ${ }^{34,35} \mathrm{Sev}$ eral studies showed that both CHIT1 activity and YKL-40 level of type 2 diabetes mellitus patients in all subgroups were higher than that of control subjects. CHIT1 activity and YKL-40 level increased gradually along with the stag- es of DN according to UACR, which was correlated with activity of CHIT1 and level of YKL-40 even after adjustment for clinical parameters, suggesting that they were both associated with kidney damage of DN patients. However, because of the higher sensitivity and specificity, CHIT1 activity was better in the diagnosis of persistent microalbuminuria compared with serum level of YKL-40. ${ }^{36,37}$

\section{Biomarkers of RAAS activation}

Renin-angiotensin-aldosterone system (RAAS) plays an important role in regulating blood pressure by producing aldosterone in human body. Angiotensinogen, produced by liver, was reported in patients with chronic glomerulonephritis in a previous study. ${ }^{38}$ The following study found that urinary angiotensinogen excretion of type 2 diabetes mellitus patients with microalbuminuria and macroalbuminuria were both significantly increased compared to control subjects, as well as to normoalbuminuric patients, suggesting that angiotensinogen appeared prior to the establishment of albuminuria. Also, angiotensinogen level shows a strong association with urinary albumin excretion, which is an indicator of the severity of kidney damage in diabetic patients. Angiotensinogen may be a promising biomarker in the early stages of DN due to its high sensitivity and specificity in diagnostic analysis of diabetic nephropathy. ${ }^{39}$

These biomarkers were summarized in Figure 1.

\section{BIOMARKERS ASSOCIATED WITH DN PATHOLOGY} Biomarkers of damage of glomerular filtration membrane

Under normal circumstances, podocyte and foot process, glomerular basement membrane and capillary endothelial cells constitute the glomerular filtration barrier. The damage of this filtration barrier can affect the glomerular filtration function. Markers such as podocytes, basement membrane and endothelial cell damage may have potential to indicate kidney damage in DN patients.

\section{Biomarkers of podocytes injury}

Studies have shown that a decline in the number of podocytes and disappearance of foot processes often occur in the early stages of DN due to apoptosis or shedding of podocytes. Therefore, urinary podocytes and their specific protein products may be regarded as potential biomarkers of podocyte injury. ${ }^{40}$ Currently, the studies focused on the podocyte-specific protein products because it was difficult to detect urinary podocytes directly. One study by Wang et al. ${ }^{41}$ showed that urinary mRNA levels of podocin, synaptopodin and nephrin in DN patients were extremely higher than those found in control subjects 


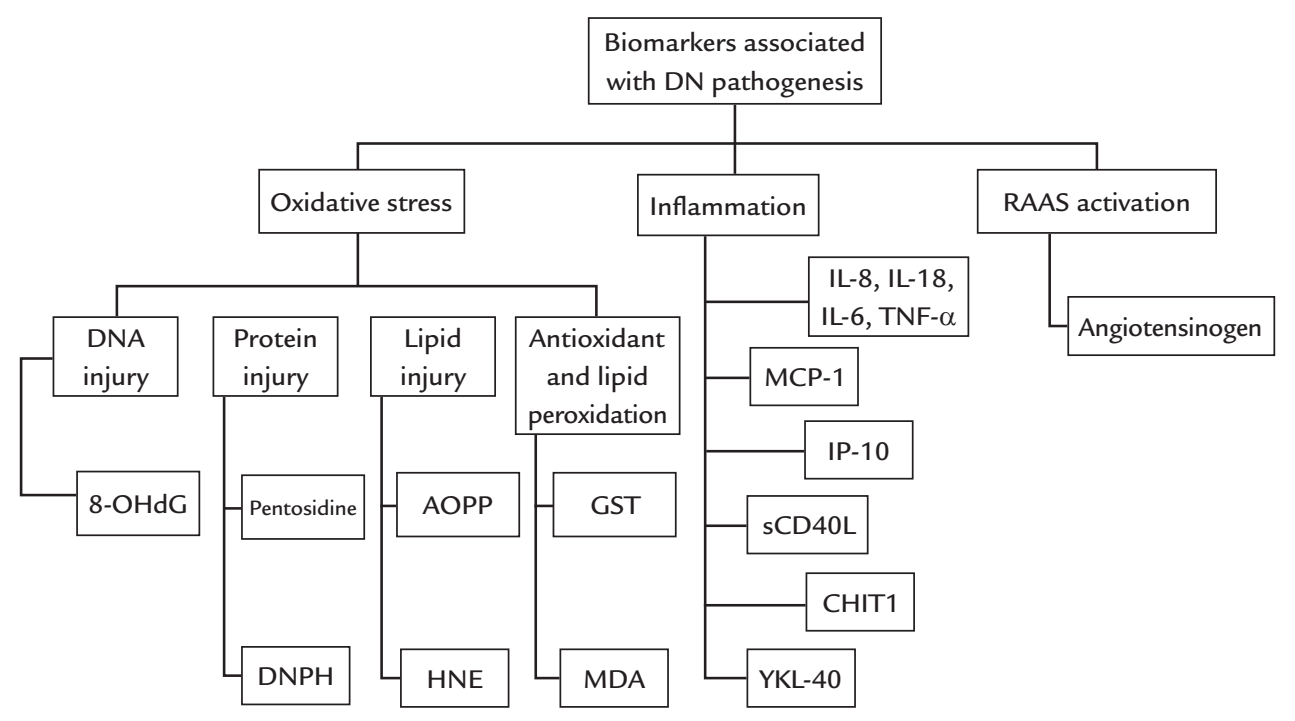

FIGURE 1 Summary of biomarkers associated with DN pathogenesis.

DN: diabetic nephropathy; RAAS: renin-angiotensin-aldosterone system; DNA: deoxyribonucleic acid; IL-8: interleukin-8; IL-18: interleukin-18; IL-6: interleukin-6; TNF- $\alpha$ : tumor necrosis factor- $\alpha$; MCP-1: monocyte chemoattractant protein-1; IP-10: interferon-inducible protein-10; 8-OHdG: 8-dihydro-2'-deoxyguanosine; AOPP: advanced oxidation protein product; GST: glutathione s-transferase; sCD40L: soluble CD40 ligand; CHIT1: chitotriosidase; DNPH: 2,4-dinitrophenylhydrazine; HNE: 4-hydroxy-nonenal; MDA: malondialdehyde; YKL-40: cartilage glycoprotein 40.

by real-time quantitative PCR. These results were also proved by renal biopsy. Also, synaptopodin level was positively correlated with urinary albumin excretion and serum creatinine concentration while negatively correlated with GFR. Patients, however, were not divided into different subgroups according to their average level of urinary protein. The validation of these podocyte-specific protein products in early stages of $\mathrm{DN}$ was not confirmed in this study. ${ }^{41}$ Further research performed by Hara et al. revealed that urinary synaptopodin level of type 2 diabetes mellitus patients complicated by nephropathy was higher when compared to control subjects, even before the occurrence of proteinuria and associated with the level of urinary albumin and $\mathrm{HbA}_{1 c}$, indicating that synaptopodin was a biomarker with high sensitivity to podocyte injury in diabetic patients. ${ }^{42}$ Another report by Jim et al. revealed that nephrin level in urine was elevated in all DN patients and $54 \%$ of normoalbuminuric subjects. In addition, urinary level of nephrin showed a strong association with UACR so that it might be a useful biomarker for nephropathic patients in preclinical stage. ${ }^{43}$

\section{Biomarkers of basement membrane injury}

Type IV collagen is the main component of the glomerular basement membrane and extracellular matrix, and does not pass through glomerular filtration barrier under normal circumstances. Therefore, type IV collagen could be used as a biomarker of basement membrane injury.
The study found that urinary type IV collagen levels were higher before microalbuminuria and associated with urinary albumin and serum creatinine, suggesting that urinary type IV collagen may be a promising biomarker for early diagnosis of DN. ${ }^{44}$

\section{Biomarkers of endothelial cells injury}

Endothelial cells injury can directly affect the permeability of the glomerular filtration membrane. Generally, von Willebrand factor (vWF) is mostly synthesized by endothelial cells. Plasma vWF levels increase when endothelial cells are stimulated or damaged. Jensen ${ }^{45}$ first discovered that plasma levels of vWF are higher in type 1 diabetes mellitus patients, indicating that there is endothelial cell dysfunction in diabetic patients. Subsequently, a number of studies have shown that plasma vWF levels in patients with DN are significantly higher than those in patients without kidney disease and control subjects, indicating that plasma $\mathrm{vWF}$ may contribute to the early diagnosis of diabetic nephropathy. ${ }^{46-48}$

Hyperglycemia does aggravate vascular endothelial injury by up-regulating the expression of adhesion molecules by endothelial cells. ${ }^{49}$ The study about type 2 diabetes mellitus patients from Malaysia discovered that plasma levels of intercellular adhesion molecule-1 (ICAM-1) are elevated in DN patients. ${ }^{50}$

Vascular endothelial growth factor (VEGF) can affect the filtration of large molecular weight proteins through 
glomerular filtration barrier by promoting endothelial cell proliferation and increasing vascular permeability. Researchers have found that plasma and urinary levels of VEGF in DN patients were both elevated. Especially in type 2 diabetes mellitus subjects, urinary VEGF level was higher in normoalbuminuric patients than in control subjects and gradually increased along with the DN stages. These findings suggested that VEGF may be an effective biomarker for early diagnosis in DN patients. ${ }^{51,52}$

\section{Biomarkers of mesangial expansion and fibrosis}

Fibrosis is one of the pathological features of diabetic complications caused by extracellular matrix alterations and mesangial expansion. Hyperglycemia up-regulates the expression of transforming growth factor- $\beta 1$ (TGF- $\beta 1$ ), which is considered to be the most crucial cytokine in glomerulosclerosis and tubulointerstitial fibrosis. ${ }^{53}$ Data by Xie showed that serum TGF- $\beta 1$ level of patients with microalbuminuria was significantly higher than that of patients with normoalbuminuria and control subjects. Interestingly, urinary levels of TGF- $\beta 1$ are already elevated in normoalbuminuria subjects and gradually increase along with DN progression, so that TGF- $\beta 1$ was considered a sensitive biomarker in the early phase of diabetic nephropathy. ${ }^{54}$

Pigment epithelial-derived factor (PEDF) is a member of the serine protease superfamily and is involved in the formation of extracellular matrix and vascular endothelial growth factor. PEDF levels were found to be decreased in the kidney of diabetic mice, suggesting that it may have a protective effect in diabetic microvascular lesions. ${ }^{55}$ Researchers also found that urinary PEDF levels in DN patients are significantly higher than in control patients, indicating that PEDF is probably an effective biomarker of DN. ${ }^{56}$

These biomarkers were summarized in Table 1.

\section{BIOMARKERS ASSOCIATED WITH RENAL FUNCTION CHANGES}

The level of proteinuria in the early stages of DN can tell us whether there is glomerular damage or not and the extent of the damage. Investigation of proteinuria continues to be the gold standard for diagnosis and staging of DN. ${ }^{57}$ In addition, albumin, transferrin (TRF), ceruloplasmin (CER) and immunoglobulin $\mathrm{G}(\mathrm{IgG})$ in urine can also reflect functional changes in glomerular filtration. Narita et al. found that urinary levels of TRF, CER and IgG in normoalbuminuric patients were significantly higher than those in control subjects and they strongly correlated with each other, indicating that TRF, CER and
IgG may be more sensitive makers for changes in filtration function than albuminuria in the early stages of $\mathrm{DN}{ }^{58}$

\section{Biomarkers of renal tubular dysfunction}

Tubulointerstitial injury plays an important role in DN development process and even prior to glomerular injury. In addition, about one third of the patients with diabetes mellitus have decreased renal function prior to proteinuria. Therefore, we should pay more attention to the biomarkers of tubulointerstitial injury, which can contribute to the early diagnosis and treatment of DN patients..$^{59,60}$

a1-Microglobulin, retinol-binding protein 4 (RBP4) and other low molecular weight proteins can freely pass through the glomerular filtration membrane and then be reabsorbed in the tubules. These were early biomarkers of tubular injury because of their increase in urine after renal tubular damage. Researchers found that urinary levels of a1-microglobulin and RBP4 in patients with normoalbuminuria were significantly higher than those in control subjects and were both associated with the levels of $\mathrm{HbA}_{1 \mathrm{c}}$, so that detection of two biomarkers may be helpful for early diagnosis of diabetic nephropathy. ${ }^{61,62}$

Some other biomarkers of tubular injury, such as neutrophil gelatinase-associated lipocalin (NGAL), $\mathrm{N}$-acetyl- $\beta$-D-glucosidase (NAG), kidney injury molecule-1 (KIM-1) and heart-type fatty acid binding protein (H-FABP) applied only to predict acute kidney injury. ${ }^{63,64}$ A recent study discovered that urinary levels of NGAL, NAG, KIM-1, H-FABP of patients with normoalbuminuria were significantly higher than those of control subjects and increased gradually along with the DN stages. In addition, they all significantly correlated with urinary albumin levels, indicating that they might be early biomarkers for DN diagnosis. ${ }^{65}$

These biomarkers were summarized in Table 2 .

\section{Conclusion}

In recent years, there has been an important achievement regarding the finding of associated biomarkers in all aspects of diabetic nephropathy. These research findings contribute greatly to our understanding of disease mechanisms. So far, there is no biomarker that can replace proteinuria. We believe that advances in research methods based on genomics, proteomics and metabolomics will provide much more convenience in future. However, we should also take all the questions into our consideration, such as the fact that there is no universally accepted standard for subject inclusion and staging, not all researches made adjustment for significant parameters and few studies have discussed the effectiveness of multi-biomarker detection. 
TABLE 1 Summary of biomarkers associated with DN pathology.

\begin{tabular}{|c|c|c|c|c|c|c|c|c|}
\hline \multirow[t]{2}{*}{ Biomarker } & \multirow[t]{2}{*}{ Mechanism } & \multirow[t]{2}{*}{ Sample } & \multirow[t]{2}{*}{ Method } & \multicolumn{3}{|l|}{ Study object } & \multirow{2}{*}{$\begin{array}{l}\text { Level } \\
\text { in DN }\end{array}$} & \multirow[t]{2}{*}{ Ref } \\
\hline & & & & T2DM & Control 1 & Control 2 & & \\
\hline Podocin & Podocytes injury & Urine & RT-QPCR & $21 \mathrm{DN}$ patients by biopsy & 9 & - & Increased & {$[42]$} \\
\hline \multirow[t]{2}{*}{ Synaptopodin } & Podocytes injury & Urine & RT-QPCR & $21 \mathrm{DN}$ patients by biopsy & 9 & - & Increased & [42] \\
\hline & & Urine & ELISA & 71 (39 normo/17 micro/15 macro) & 69 & - & Increased ${ }^{\#}$ & [43] \\
\hline \multirow[t]{2}{*}{ Nephrin } & Podocytes injury & Urine & RT-QPCR & $21 \mathrm{DN}$ patients by biopsy & 9 & - & Increased & {$[42]$} \\
\hline & & Urine & ELISA & 66 (26 normo/11 micro/29 macro) & 10 & - & Increased ${ }^{\#}$ & {$[44]$} \\
\hline $\begin{array}{l}\text { Type IV } \\
\text { collagen }\end{array}$ & $\begin{array}{l}\text { Basement } \\
\text { membrane injury }\end{array}$ & Urine & ELISA & $\begin{array}{l}698 \mathrm{DM} \text { ( } 264 \text { normo/169 micro/181 } \\
\text { macro/84 renal failure) }\end{array}$ & 191 & - & Increased & [45] \\
\hline \multirow[t]{3}{*}{ vWF } & $\begin{array}{l}\text { Endothelial } \\
\text { cells injury }\end{array}$ & Plasma & ELISA & 109 (66 normo/26 micro/17 macro) & - & $\begin{array}{l}31 \\
\text { nondiabetic }\end{array}$ & Increased & {$[47]$} \\
\hline & & Plasma & ELISA & 24 (12 normo/12 micro) & 12 & - & Increased & {$[48]$} \\
\hline & & Serum & ELISA & $60(30 \mathrm{DN} / 30$ without $\mathrm{DN})$ & 60 & - & Increased & [49] \\
\hline \multirow[t]{2}{*}{ VEGF } & $\begin{array}{l}\text { Endothelial } \\
\text { cells injury }\end{array}$ & plasma & ELISA & 387 T1DM (188 normo/199 DN) & - & - & Increased & {$[52]$} \\
\hline & & Urine & ELISA & $\begin{array}{l}107 \text { ( } 37 \text { normo/37 micro/ } \\
33 \text { proteinuria) }\end{array}$ & 47 & - & Increased ${ }^{\#}$ & {$[53]$} \\
\hline TGF- $\beta 1$ & $\begin{array}{l}\text { Mesangial } \\
\text { expansion/fibrosis }\end{array}$ & $\begin{array}{l}\text { Serum/ } \\
\text { urine }\end{array}$ & ELISA & 54 (20 normo/34 micro) & 30 & - & Increased & {$[55]$} \\
\hline PEDF & $\begin{array}{l}\text { Mesangial } \\
\text { expansion/fibrosis }\end{array}$ & Urine & ELISA & $\begin{array}{l}228 \text { (59 normo/130 micro/ } \\
39 \text { macro) }\end{array}$ & 46 & - & Increased & {$[57]$} \\
\hline
\end{tabular}

DN: diabetic nephropathy; T2DM: type 2 diabetes mellitus; Ref: reference; RT-QPCR: real-time quantitative polymerase chain reaction; ELISA: enzyme-linked immunesorbent assay; normo: normoalbuminuria; micro: microalbuminuria; macro: macroalbuminuria; DM: diabetes mellitus; vWF: von Willebrand factor; VEGF: vascular endothelial growth factor; T1DM: type 1 diabetes mellitus; TGF- $\beta 1$ : transforming growth factor- $\beta 1$; PEDF: pigment epithelial-derived factor.

Control 1: healthy subjects; Control 2: not healthy subjects.

\#: increased prior to albuminuria.

\section{TABLE 2 Summary of biomarkers associated with renal function changes.}

\begin{tabular}{|c|c|c|c|c|c|c|c|c|}
\hline \multirow[t]{2}{*}{ Biomarker } & \multirow[t]{2}{*}{ Mechanism } & \multirow[t]{2}{*}{ Sample } & \multirow[t]{2}{*}{ Method } & \multicolumn{3}{|l|}{ Study object } & \multirow{2}{*}{$\begin{array}{l}\text { Level } \\
\text { in DN }\end{array}$} & \multirow[t]{2}{*}{ Ref } \\
\hline & & & & T2DM & Control 1 & Control 2 & & \\
\hline TRF/CER/IgG & $\begin{array}{l}\text { Glomerular } \\
\text { dysfunction }\end{array}$ & Urine & IRMA & 61 (61 normo) & 17 & - & Increased & {$[59]$} \\
\hline a1-microglobulin & $\begin{array}{l}\text { Renal tubular } \\
\text { dysfunction }\end{array}$ & Urine & $\begin{array}{l}\text { Latex } \\
\text { immunoassay }\end{array}$ & $\begin{array}{l}587 \text { (375 normo/181 } \\
\text { micro/31 macro) }\end{array}$ & - & - & Increased & [62] \\
\hline RBP & $\begin{array}{l}\text { Renal tubular } \\
\text { dysfunction }\end{array}$ & Urine & ELISA & 59 T1DM (48 normo/11 micro) & 40 & - & Increased & [63] \\
\hline $\begin{array}{l}\text { NGAL/NAG/ } \\
\text { KIM-1/H-FABP }\end{array}$ & $\begin{array}{l}\text { Renal tubular } \\
\text { dysfunction }\end{array}$ & Urine & ELISA & $\begin{array}{l}94 \mathrm{DM} \text { (41 normo/41 } \\
\text { micro/12 macro) }\end{array}$ & - & $\begin{array}{l}45 \\
\text { nondiabetic }\end{array}$ & Increased ${ }^{\#}$ & {$[66]$} \\
\hline
\end{tabular}

T2DM: type 2 diabetes mellitus; Ref: reference; TRF: transferrin; CER: ceruloplasmin; IgG: immunoglobulin G; IRMA: immunoradiometric assay; normo: normoalbuminuria; micro: microalbuminuria; macro: macroalbuminuria; RBP: retinol-binding protein; ELISA: enzyme-linked immunosorbent assay; T1DM: type 1 diabetes mellitus; NGAL: neutrophil gelatinase-associated lipocalin; NAG: $N$-acetyl- $\beta$-D-glucosidase; KIM-1: kidney injury molecule-1; H-FABP: heart-type fatty acid binding protein; DM: diabetes mellitus.

Control 1: healthy subjects; control 2: not healthy subjects.

\#: increased prior to albuminuria.

\section{REFERENCES}

1. Shaw JE, Sicree RA, Zimmet PZ. Global estimates of the prevalence of diabetes for 2010 and 2030. Diabetes Res Clin Pract. 2010; 87(1):4-14.

2. Gross JL, Azevedo MJ, Silveiro SP, Canani LH, Caramori ML, Zelmanovitz T. Diabetic nephropathy: diagnosis, prevention, and treatment. Diabetes Care. $2005 ; 28(1): 164-76$.
3. Tabaei BP, Al-Kassab AS, Ilag LL, Zawacki CM, Herman WH. Does microalbuminuria predict diabetic nephropathy? Diabetes Care. 2001; 24(9):1560-6

4. Diabetes Control and Complications Trial Research Group, Nathan DM, Genuth $\mathrm{S}$, Lachin J, Cleary P, Crofford O, Davis M, et al. The effect of intensive treatment of diabetes on the development and progression of long-term complications in insulin-dependent diabetes mellitus. N Engl J Med. 1993; 329(14):977-86. 
5. Intensive blood-glucose control with sulphonylureas or insulin compared with conventional treatment and risk of complications in patients with type 2 diabetes (UKPDS 33). UK Prospective Diabetes Study (UKPDS) Group. The Lancet. 1998; 352(9131):837-53

6. Brownlee M. Biochemistry and molecular cell biology of diabetic complications. Nature. 2001; 414(6865):813-20.

7. Cooper ME. Pathogenesis, prevention, and treatment of diabetic nephropathy. Lancet. 1998; 352(9123):213-9.

8. Forbes JM, Coughlan MT, Cooper ME. Oxidative stress as a major culprit in kidney disease in diabetes. Diabetes. 2008; 57(6):1446-54.

9. Giacco F, Brownlee M. Oxidative stress and diabetic complications. Circ Res. 2010; 107(9):1058-70.

10. Ha H, Kim C, Son Y, Chung MH, Kim KH. DNA damage in the kidneys of diabetic rats exhibiting microalbuminuria. Free Radic Biol Med. 1994; 16(2):271-4.

11. Hinokio Y, Suzuki S, Hirai M, Chiba M, Hirai A, Toyota T. Oxidative DNA damage in diabetes mellitus: its association with diabetic complications. Diabetologia. 1999; 42(8):995-8.

12. Zhao L, Xiang G, Yang L, Sun H, Le L, Liu Y. Relationship of serum 8-OHdG and VEGF with diabetic nephropathy in diabetics. Chin J Diabetes. 2012; 20(9):667-70.

13. Serdar M, Sertoglu E, Uyanik M, Tapan S, Akin K, Bilgi C, et al. Comparison of 8-hydroxy-2'-deoxyguanosine (8-OHdG) levels using mass spectrometer and urine albumin creatinine ratio as a predictor of development of diabetic nephropathy. Free Radic Res. 2012; 46(10):1291-5.

14. Calabrese V, Mancuso C, Sapienza M, Puleo E, Calafato S, Cornelius C, et al. Oxidative stress and cellular stress response in diabetic nephropathy. Cell Stress Chaperones. 2007; 12(4):299-306.

15. Tabak O, Gelisgen R, Erman H, Erdenen F, Muderrisoglu C, Aral H, et al. Oxidative lipid, protein, and DNA damage as oxidative stress markers in vascular complications of diabetes mellitus. Clin Invest Med. 2011; 34(3):E163-71.

16. Jiang B, Guo L, Li BY, Zhen JH, Song J, Peng T, et al. Resveratrol attenuates early diabetic nephropathy by down-regulating glutathione s-transferases Mu in diabetic rats. J Med Food. 2013; 16(6):484-6.

17. Ahmed S, Mundhe N, Borgohain M, Chowdhury L, Kwatra M, Bolshette N, et al. Diosmin modulates the NF-kB signal transduction pathways and downregulation of various oxidative stress markers in alloxan-induced diabetic nephropathy. Inflammation. 2016; 39(5):1783-97.

18. Kishore L, Kaur N, Singh R. Renoprotective effect of Bacopa monnieri via inhibition of advanced glycation end products and oxidative stress in STZnicotinamide-induced diabetic nephropathy. Ren Fail. 2016; 38(9):1528-44.

19. Datta SK, Kumar V, Ahmed RS, Tripathi AK, Kalra OP, Banerjee BD. Effect of GSTM1 and GSTT1 double deletions in the development of oxidative stress in diabetic nephropathy patients. Indian J Biochem Biophys. 2010; 47(2):100-3.

20. Annadurai T, Vasanthakumar A, Geraldine P, Thomas PA. Variations in erythrocyte antioxidant levels and lipid peroxidation status and in serum lipid profile parameters in relation to blood haemoglobin A1c values in individuals with type 2 diabetes mellitus. Diabetes Res Clin Pract. 2014; 105(1):58-69.

21. Giebułtowicz J, Sołobodowska S, Bobilewicz D, Wroczyński P. Blood ALDH1 and GST activity in diabetes type 2 and its correlation with glycated hemoglobin. Exp Clin Endocrinol Diabetes. 2014; 122(1):55-9.

22. Noce A, Fabrini R, Dessi M, Bocedi A, Santini S, Rovella V, et al. Erythrocyte glutathione transferase activity: a possible early biomarker for blood toxicity in uremic diabetic patients. Acta Diabetol. 2014; 51(2):219-24.

23. Liu J, Zhao Z, Willcox MD, Xu B, Shi B. Multiplex bead analysis of urinary cytokines of type 2 diabetic patients with normo- and microalbuminuria. J Immunoassay Immunochem. 2010; 31(4):279-89.

24. Moriwaki Y, Yamamoto T, Shibutani Y, Aoki E, Tsutsumi Z, Takahashi S, et al. Elevated levels of interleukin-18 and tumor necrosis factor-alpha in serum of patients with type 2 diabetes mellitus: relationship with diabetic nephropathy. Metabolism. 2003; 52(5):605-8.

25. Navarro JF, Mora C, Gomez M, Muros M, Lopez-Aguilar C, García J. Influence of renal involvement on peripheral blood mononuclear cell expression behavior of tumour necrosis factor-alpha and interleukin- 6 in type 2 diabetic patients. Nephrol Dial Transplant. 2008; 23(3):919-26.

26. Shikano M, Sobajima H, Yoshikawa H, Toba T, Kushimoto H, Katsumata $\mathrm{H}$, et al. Usefulness of a highly sensitive urinary and serum IL- 6 assay in patients with diabetic nephropathy. Nephron. 2000; 85(1):81-5.

27. Dimas G, Iliadis F, Tegos T, Spiroglou S, Kanellos I, Karamouzis I, et al. 4B.08: serum levels of TIMP-1 and IL-6 are associated with hypertension and atherosclerosis in patients with early stages of chronic kidney disease and type 2 diabetic nephropathy. J Hypertens. 2015; 33(Suppl 1):e55.

28. Zhang C, Xiao C, Wang P, Xu W, Zhang A, Li Q, et al. The alteration of Th1/ Th2/Th17/Treg paradigm in patients with type 2 diabetes mellitus: Relationship with diabetic nephropathy. Hum Immunol. 2014; 75(4):289-96

29. Dalla Vestra M, Mussap M, Gallina P, Bruseghin M, Cernigoi AM, Saller A, et al. Acute-phase markers of inflammation and glomerular structure in patients with type 2 diabetes. J Am Soc Nephrol. 2005; 16(Suppl 1):S78-82.

30. Navarro JF, Mora C, Muros M, García J. Urinary tumour necrosis factoralpha excretion independently correlates with clinical markers of glomerular and tubulointerstitial injury in type 2 diabetic patients. Nephrol Dial Transplant. 2006; 21(12):3428-34.

31. Wu CC, Chen JS, Lu KC, Chen CC, Lin SH, Chu P, et al. Aberrant cytokines/ chemokines production correlate with proteinuria in patients with overt diabetic nephropathy. Clin Chim Acta. 2010; 411(9-10):700-4.

32. El-Asrar MA, Adly AA, Ismail EA. Soluble CD40L in children and adolescents with type 1 diabetes: relation to microvascular complications and glycemic control. Pediatr Diabetes. 2012; 13(8):616-24.

33. Chiarelli F, Giannini C, Verrotti A, Mezzetti A, Mohn A. Increased concentrations of soluble CD40 ligand may help to identify type 1 diabetic adolescents and young adults at risk for developing persistent microalbuminuria. Diabetes Metab Res Rev. 2008; 24(7):570-6.

34. Kanneganti M, Kamba A, Mizoguchi E. Role of chitotriosidase (chitinase 1) under normal and disease conditions. J Epithel Biol Pharmacol. 2012; 5:1-9.

35. Rathcke CN, Vestergaard H. YKL-40, a new inflammatory marker with relation to insulin resistance and with a role in endothelial dysfunction and atherosclerosis. Inflamm Res. 2006; 55(6):221-7.

36. Røndbjerg AK, Omerovic E, Vestergaard H. YKL-40 levels are independently associated with albuminuria in type 2 diabetes. Cardiovasc Diabetol. 2011; 10:54.

37. Żurawska-Płaksej E, Ługowska A, Hetmańczyk K, Knapik-Kordecka M, Adamiec R, Piwowar A. Proteins from the 18 glycosyl hydrolase family are associated with kidney dysfunction in patients with diabetes type 2 Biomarkers. 2015; 20(1):52-7.

38. Urushihara M, Kondo S, Kagami S, Kobori H. Urinary angiotensinogen accurately reflects intrarenal renin-angiotensin system activity. Am J Nephrol. 2010; 31(4):318-25

39. Satirapoj B, Siritaweesuk N, Supasyndh O. Urinary angiotensinogen as a potential biomarker of diabetic nephropathy. Clin Kidney J. 2014; 7(4):354-60.

40. Reddy GR, Kotlyarevska K, Ransom RF, Menon RK. The podocyte and diabetes mellitus: is the podocyte the key to the origins of diabetic nephropathy? Curr Opin Nephrol Hypertens. 2008; 17(1):32-6.

41. Wang G, Lai FM, Lai KB, Chow KM, Li KT, Szeto CC. Messenger RNA expression of podocyte-associated molecules in the urinary sediment of patients with diabetic nephropathy. Nephron Clin Pract. 2007; 106(4):c169-79.

42. Hara M, Yamagata K, Tomino Y, Saito A, Hirayama Y, Ogasawara S, et al. Urinary podocalyxin is an early marker for podocyte injury in patients with diabetes: establishment of a highly sensitive ELISA to detect urinary podocalyxin. Diabetologia. 2012; 55(11):2913-9.

43. Jim B, Ghanta M, Qipo A, Fan Y, Chuang PY, Cohen HW, et al. Dysregulated nephrin in diabetic nephropathy of type 2 diabetes: a cross sectional study. PLoS One. 2012; 7(5):e36041.

44. Tomino Y, Suzuki S, Azushima C, Shou I, Iijima T, Yagame M, et al. Asian multicenter trials on urinary type IV collagen in patients with diabetic nephropathy. J Clin Lab Anal. 2001; 15(4):188-92.

45. Jensen T. Increased plasma concentration of von Willebrand factor in insulin dependent diabetics with incipient nephropathy. BMJ. 1989; 298(6665):27-8.

46. Yu Y, Suo L, Yu H, Wang C, Tang $\mathrm{H}$. Insulin resistance and endothelial dysfunction in type 2 diabetes patients with or without microalbuminuria. Diabetes Res Clin Pract. 2004; 65(2):95-104.

47. Hirano T, Ookubo K, Kashiwazaki K, Tajima H, Yoshino G, Adachi M. Vascular endothelial markers, von Willebrand factor and thrombomodulin index, are specifically elevated in type 2 diabetic patients with nephropathy: comparison of primary renal disease. Clin Chim Acta. 2000; 299(1-2):65-75

48. Fang YH, Zhang JP, Zhou SX, Zheng JF, Yu YW, Yan SG, et al. [Relationship between serum vWF and PAF in type 2 diabetic patients and diabetic nephropathy]. Di Yi Jun Yi Da Xue Xue Bao. 2005; 25(6):729-31.

49. Nong S, Ke L, Zhang X, Huang X, Man Y, Wang S, et al. Mechanism underlying up-regulation of ICAM-1 and VCAM-1 expressions induced by high glucose in endothelial cells. Chinese J Cardiovasc Med. 2010; 15(3):219-22.

50. Abu Seman N, Anderstam B, Wan Mohamud WN, Östenson CG, Brismar $\mathrm{K}, \mathrm{Gu} \mathrm{HF}$. Genetic, epigenetic and protein analyses of intercellular adhesion 
molecule 1 in Malaysian subjects with type 2 diabetes and diabetic nephropathy. J Diabetes Complications. 2015; 29(8):1234-9.

51. Hovind P, Tarnow L, Oestergaard PB, Parving HH. Elevated vascular endothelial growth factor in type 1 diabetic patients with diabetic nephropathy. Kidney Int Suppl. 2000; 75:S56-61.

52. Kim NH, Kim KB, Kim DL, Kim SG, Choi KM, Baik SH, et al. Plasma and urinary vascular endothelial growth factor and diabetic nephropathy in Type 2 diabetes mellitus. Diabet Med. 2004; 21(6):545-51.

53. Tamaki K, Okuda S. Role of TGF-beta in the progression of renal fibrosis. Contrib Nephrol. 2003; 139:44-65.

54. Xie F. Significance of serum and urinary TGF- $\beta 1$ to the early diagnosis of diabetic nephropathy. Strait Pharmaceutical J. 2009; 21(5):145-6.

55. Wang JJ, Zhang SX, Lu K, Chen Y, Mott R, Sato S, et al. Decreased expression of pigment epithelium-derived factor is involved in the pathogenesis of diabetic nephropathy. Diabetes. 2005; 54(1):243-50.

56. Chen H, Zheng Z, Li R, Lu J, Bao Y, Ying X, et al. Urinary pigment epitheliumderived factor as a marker of diabetic nephropathy. Am J Nephrol. 2010; 32(1):47-56.

57. Cohen-Bucay A, Viswanathan G. Urinary markers of glomerular injury in diabetic nephropathy. Int J Nephrol. 2012; 2012:146987.

58. Narita T, Sasaki H, Hosoba M, Miura T, Yoshioka N, Morii T, et al. Parallel increase in urinary excretion rates of immunoglobulin $\mathrm{G}$, ceruloplasmin, transferrin, and orosomucoid in normoalbuminuric type 2 diabetic patients. Diabetes Care. 2004; 27(5):1176-81.

59. Gewin L, Zent R, Pozzi A. Progression of chronic kidney disease: too much cellular talk causes damage. Kidney Int. 2017; 91(3):552-60.

60. Perkins BA, Ficociello LH, Silva KH, Finkelstein DM, Warram JH, Krolewski AS. Regression of microalbuminuria in type 1 diabetes. N Engl J Med. 2003; 348(23):2285-93

61. Hong CY, Hughes $\mathrm{K}$, Chia KS, Ng V, Ling SL. Urinary alpha1-microglobulin as a marker of nephropathy in type 2 diabetic Asian subjects in Singapore. Diabetes Care. 2003; 26(2):338-42

62. Salem MA, el-Habashy SA, Saeid OM, el-Tawil MM, Tawfik PH. Urinary excretion of n-acetyl-beta-D-glucosaminidase and retinol binding protein as alternative indicators of nephropathy in patients with type 1 diabetes mellitus. Pediatr Diabetes. 2002; 3(1):37-41.

63. Bagshaw SM, Bellomo R. Early diagnosis of acute kidney injury. Curr Opin Crit Care. 2007; 13(6):638-44

64. Han WK, Wagener G, Zhu Y, Wang S, Lee HT. Urinary biomarkers in the early detection of acute kidney injury after cardiac surgery. Clin J Am Soc Nephrol. 2009; 4(5):873-82.

65. Nauta FL, Boertien WE, Bakker SJ, van Goor H, van Oeveren W, Jong PE, et al. Glomerular and tubular damage markers are elevated in patients with diabetes. Diabetes Care. 2011;34(4):975-81. 